TI 2011-051/2

Tinbergen Institute Discussion Paper

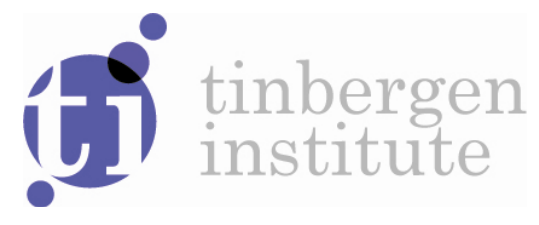

\title{
Gender Differences, HIV Risk Perception and Condom Use
}

Judith Lammers ${ }^{1}$

Sweder van Wijnbergen'

Daan Willebrands²

' Faculty of Economics and Business, University of Amsterdam;

${ }_{2}^{2}$ Amsterdam Institute for International Development (AIID), Amsterdam. 
Tinbergen Institute is the graduate school and research institute in economics of Erasmus University Rotterdam, the University of Amsterdam and VU University Amsterdam.

More TI discussion papers can be downloaded at http://www.tinbergen.nl

Tinbergen Institute has two locations:

Tinbergen Institute Amsterdam

Gustav Mahlerplein 117

1082 MS Amsterdam

The Netherlands

Tel.: +31(0)205251600

Tinbergen Institute Rotterdam

Burg. Oudlaan 50

3062 PA Rotterdam

The Netherlands

Tel.: +31(0)10 4088900

Fax: +31(0)104089031

Duisenberg school of finance is a collaboration of the Dutch financial sector and universities, with the ambition to support innovative research and offer top quality academic education in core areas of finance.

DSF research papers can be downloaded at: http://www.dsf.nl/

Duisenberg school of finance

Gustav Mahlerplein 117

1082 MS Amsterdam

The Netherlands

Tel.: +31(0)20 5258579 


\title{
Gender differences, HIV risk perception and condom use
}

\author{
By Judith Lammers (J.Lammers@uva.nl), \\ Sweder van Wijnbergen (svanwijnbergen@gmail.com), \\ Daan Willebrands (D.Willebrands@gmail.com)
}

March 2011

\begin{abstract}
This paper analyzes how different types of HIV-knowledge influence condom use across the sexes. The empirical work is based on a household survey conducted among 1,979 households of a representative group of market persons in Lagos in 2008. Last time condom use is analyzed based on a Probit model while correcting for clustering effects. Next to socioeconomic characteristics, the data includes questions on knowledge of the existence of HIV, HIV prevention, HIV stigma, intended pregnancy, and risk perceptions of engaging in unprotected sex.

We observe a large HIV knowledge gap between males and females. Moreover, across the sexes different type of knowledge are important in condom use. Low risk perceptions of engaging in unprotected sex and not knowing that condoms prevent HIV infection appear to be the best predictors for risky sexual behavior among men. The latter is also important in condom use among single females. Both factors, however, do not explain sexual behavior of married women, suggesting a lack of bargaining power in HIV prevention decisions among married females. For females, irrespectively of marital status, stigma leads to lower condom use. Obviously, lack of knowledge on where condoms are available (still 9.4\%, 29.1\% of the male and female respondents respectively) reduced condom use across both males and females.

Our results call for programmatic approaches to differente the focus of HIV prevention campaigns for males and females including a separate focus for the married. Moreover, the large predictive power of high-risk perceptions of engaging in unprotected sex (while correcting for other HIV knowledge indicators) calls for further exploration of influencing these risk perceptions in HIV prevention programs.
\end{abstract}

Keywords: $\quad$ prevention, knowledge, HIV/AIDS, risk perception, gender, condom use

JEL classification: I1, I2

The authors are grateful for all colleagues and parties involved in setting up the unique dataset used in this paper: The Health Insurance Fund (HIF), The Netherlands Ministry of Foreign Affairs, the PharmAccess Foundation, the Center for Poverty related Communicable Diseases (CPCD), the Lagos University Teaching Hospital (LUTH), and the Amsterdam Institute for International Development (AIID). Special gratitude to Damien de Walque, Prof. J.M. Baland and other participants of the annual workshop on the Economics of AIDS. Moreover, we thank Ton Vriend for sharing his experiences in HIV prevention in Swaziland based on which we started analyzing the gender differences. 


\section{Introduction}

Understanding into why people engage in unprotected sex given the severe consequences that it may lead to is of major importance in reducing the global spread of HIV. Although local and international interventions, including extensive HIV prevention programs, have improved HIV knowledge and awareness around the globe (UNAIDS, 2008; p 100) many new infections daily take place. In 2008, 2.7 million new infections took place, with 71\% of those in Sub-Saharan Africa (UNAIDS, 2009). Although HIV rates are showing signs of leveling off (UNAIDS, 2008) in recent years, HIV prevalence rates are not decreasing as fast as hoped for given the large amount of effort and money spend on HIV prevention. It therefore remains important to gain a better understanding of what specific knowledge and awareness factors have actually increased the use of preventive measures, so as to better focus prevention efforts.

In Sub-Saharan Africa HIV affects women disproportionately: they account for $60 \%$ of the HIV infections (UNAIDS, 2008). This is often attributed to biological reasons (e.g. Royce et al. 1997), socio-economic status (e.g. Seeley, 1994), or lack of bargaining power preventing use of preventive measures (Dunkle et al. 2004). Moreover, in western Africa, the number of women with comprehensive HIV knowledge is found to be 10-20\% lower than men (Lowndes et al. 2008). These differences have lead to many prevention programs focused on women. ${ }^{1}$ However, if it is in particular culture or a lack of female bargaining power, HIV prevention campaigns might be more efficient when focused towards males. In diversifying prevention campaigns across gender, it is important to know which types of knowledge are relevant for each of them. In other words, what type of information works and what does not for each of the sexes? This paper analyzes this question using data from a large households survey conducted among market persons in Nigeria's financial capital Lagos in 2008, subsequently called the "Lagos Market Survey" or LMS. Although Nigeria's HIV prevalence rates are relatively low compared to Eastern and Southern Africa, recent data show that AIDS is a growing public health problem in Nigeria. Since 2000, the number of AIDS orphans has grown from 360,000 to 1,200,000 in 2007 (UNSTATS, July $30^{\text {th }} 2008$ ). In the same year, $3.6 \%$ of its population was found to carry the virus based on a national population based survey that included HIV testing (UNAIDS, 2009)

Globally, HIV knowledge has thus far been increased on two levels: first, awareness of the existence and ways of transmission of HIV has been promoted. This has been relatively successful: in 2004, over $90 \%$ of the Nigerian population had heard of HIV/AIDS (NLSS, 2004). Second, ways of preventing infection with HIV have been communicated. The famous ABC

\footnotetext{
${ }^{1}$ This focus is supported by the UNAIDS policy paper on HIV prevention which mentions women and girls as one of the key populations to target HIV prevention (UNAIDS 2005).
} 
(Abstain, Be faithful, use Condom) has now been incorporated in most prevention campaigns all around the world. This campaign too seems to have paid off: $80.8 \%$ of the respondents of the Lagos Market Survey who had ever heard of HIV/AIDS mention at least one of the ABC as a possible method to prevent HIV infection. ${ }^{2}$ In the Okambilimbilim Survey, a household survey conducted in the same year in Windhoek, Namibia, this is even higher: 90.6\% (AIID-CPCD, $2009 \mathrm{~b}) .^{3}$

Despite this knowledge, people still engage in unprotected sex, even in countries with high HIV prevalence rates, where unprotected sex entails high risks. And many studies have shown low levels of condom use (e.g. De Walque 2009; Birraro et al. 2009; Ahmed et al. 2001), irrespective of infection risks. For example, among respondents ${ }^{4}$ in the Lagos Market Survey that indicated to have more than one sexual partner, $34.7 \%$ did not use a condom the last time they had sexual intercourse ${ }^{5}$. In the Okambilimbilim Survey in Windhoek, this was only a little lower with $33.9 \%$ in 2008 . The small size of the difference is striking, as the prevalence rate is much higher among the Namibian respondents. $12.0 \%$ of the Namibian respondents was HIV positive compared to $1.4 \%$ in the Lagos Market Survey ${ }^{6}$. The result has been confirmed by the more systematic analysis of Lagarde et al. (2001). They study condom use in four different cities in SubSaharan Africa, and do not find significant higher condom use among populations with higher HIV prevalence rates. Sahlu et al. (1999) find a similar result among factory workers with a high prevalence rate in Ethopia where condom use is low, even though knowledge on condoms is widely spread. Opio et al. (2008) even show an increase in some sexual behaviors in Uganda over the period 1989-2005: although abstinence increased among 15-24 old adolescents from 23\% in 1989 to $42 \%$ in 2005, males (15-49) were found to report more multiple sexual partnerships and sex with non-spousal partners over the period 2001 - $2005(25 \%-29 \%$, and $28 \%-37 \%$ respectively) while among male adolescents condom use with non-spousal partners declined from $65 \%$ to $55 \%$. This risky sexual behavior is remarkable given the prevention knowledge and reduced risk of HIV contraction when condoms are used consistently (e.g. Weller \& Davis, 2002; Pinkerton \& Abramson, 1997).

The evidence on the impact of a change in knowledge on condom use is nevertheless mixed. Macintyre et al. (2001), for example, find a positive effect of knowledge of HIV prevention methods on protective sexual behavior for their sample covering Uganda, Kenya and

\footnotetext{
${ }^{2}$ Note, however, that knowledge of all three is rather low, $4.8 \%$ among the same respondents.

${ }^{3}$ The first and third author have been highly involved in the organization and implementation of both the LMS and this survey, which have a comparable design.

${ }^{4}$ Aged 12 years and older

${ }^{5}$ Note that the average number of sexual partners is 2.9 .

${ }^{6}$ Both rates are not corrected for a potential non-response bias.
} 
Zambia. Similarly, Magnani et al. (2002) find a positive effect of knowledge on condom use in Zambia. But several other studies show little impact on condom use of increased knowledge of its protective benefits (e.g. Williams et al. 2003).

Risky sexual behavior in spite of preventive knowledge is less surprising if people are unaware of their risk of contracting HIV when having unprotected sex. If people are not aware of the level of risk that their activities involve, knowledge on preventive measures as such will not reduce the risks taken. The degree of riskiness of unprotected sex is not often addressed in HIV prevention campaigns. And neither are evaluations on the relation between risk perception and preventive behavior widely incorporated in the empirical research on condom use. Among the exceptions, Meekers and Klein (2002) find that risk perception is positively related to condom use among young people in urban Cameroon, but their results are only significant when looking at males with a casual partner. The study by Prata et al. (2006) also looks at the perception of the individual on his or her chances of getting HIV. However, in their analysis on condom use, they only include a dummy variable for 'correct perception' of the risk by the individual, and not the level of perception of the risk as such. They find weak evidence for a positive relationship between correct risk perception and condom use.

But it is the actual perception of the risks by the individual that matters in their decision making, not whether that perception is known by us to be correct or incorrect. We therefore analyze the relation of risk perception on preventive behavior directly, together with standard knowledge indicators. In a Probit model for last time condom use, controlling for socioeconomic characteristics, we show that the perceived level of risk has large predictive power, but for males' condom use only. An explanation for the irrelevance of risk perception and HIV prevention knowledge among females could be a lack of bargaining power of married females or a general tendency not to use a condom during sexual intercourse with the spouse when married. Although the lack of females' bargaining power in sexual practices has frequently been addressed in the literature (e.g. Dunkle et al. 2004), our results contradict Pranitha \& Cleland (2005), who find that it is the women's risk perception which influences condom use.

Our survey data shed new light on the impact of the different, more frequently used, HIV knowledge indicators on risky sexual behavior across the sexes as well. The indicators include; knowledge on the existence of HIV, prevention knowledge, condom knowledge, knowledge on where to get condoms, stigma, and HIV misperceptions. Knowledge of the HIV preventive characteristics of condoms has a significant impact on condom use for single women and for males in general (even when correcting for risk perceptions), but not for married women. Notable is that HIV stigma and HIV misperceptions explain low condom usage by females 
irrespectively of marital status. For both sexes, the knowledge of where to get a condom is essential in explaining condom use ${ }^{7}$. Lack of this knowledge is more prevalent among females $(29.1 \%$ versus $9.4 \%)$.

We provide the following results, which we think are highly policy relevant: We confirm the large knowledge gap between males and females as shown by Lowndes et al. (2008) in our sample. On almost all HIV knowledge types, males score better than females, but in particular the knowledge on condoms is substantially lower among the women studied. Different types of HIV knowledge influence the propensity to use condoms differently across marital status and the sexes. Creating a different focus of HIV prevention campaigns for males and females, and a separate focus for the married could enhance protected sex. In particular, if our results can be extrapolated from, prevention campaigns aiming at improving risk perception and condom knowledge among males should be stressed more to reduce new infections around the globe.

\section{Data}

\subsection{Lagos Market Survey 2008}

This paper uses data collected for the "Lagos Market Survey" in 2008, which includes responses from 1,979 low and middle-income families of market persons in Lagos, the financial capital of Nigeria. ${ }^{8}$ Out of 59 markets, 16 markets were randomly selected, stratified by area and selected with probability proportional to size. Market persons and their households were approached based on listings provided by the market leaders. Interviews took mainly place in the household dwelling and interviewers aimed at interviewing all household members privately and separately. Local interviewers were trained during an extensive two-week training program, which included role-plays and actual field tests. The household survey gathered information covering a unique variety of Millennium Development Goals related topics in both the socioeconomic and biomedical field. ${ }^{9}$ The first also included a section on risk behavior and perceptions. The latter contained several questions related to HIV knowledge and perception but also on sexual experience and behavior and was administered by an interviewer with a medical background. In addition to this self-reported biomedical information, adult household members were screened

\footnotetext{
${ }^{7}$ This is not as trivial as it may sound, one could also ask the partner to get the condoms.

8 The Lagos Market Survey 2008 actually served as a baseline survey to assess the impact of subsidized health insurance for low-income families in Nigeria, provided under a program funded by the Dutch government.

${ }^{9}$ In order of the questionnaires they include questions on; demographics, education, health, healthcare usage \& expenditures, trust, employment \& income, business \& market activity, health insurance (access and willingness-topay), housing \& sanitation, household assets, food \& non-food consumption, mortality, financial decision-making, self-reported health status, health knowledge \& prevention behavior for diseases like diabetes, high blood pressure, malaria, and HIV/AIDS.
} 
for several diseases including HIV/AIDS after giving formal consent. ${ }^{10}$ The Lagos State Government Ministry of Health gave approval for the survey and ethical clearance was received from the ethical committee of The Lagos University Teaching Hospital (LUTH). A detailed description of the survey methodology and the characteristics of the households can be found in the baseline survey report (AIID-CPCD, 2009a).

Most of the information was collected for all household members of the market persons, but we focus on the financial decision-maker of the household, because only this person was asked to answer the subset of questions on risk perceptions in the survey. In the household survey, $49.5 \%$ of the financial decision-makers, or "household heads" ${ }^{11}$, were male, providing an equal share of males and females in our sample. The marital status of these household heads does not significantly differ across the sexes; $66.9 \%$ of the males reported to be married and $69.2 \%$ of the females $\left(\mathrm{p}=0.27^{12}\right)$. Their age ranged from $18-100$ with an average age of 41.3 years. The average annual income they obtained from work is $466,468 \mathrm{Naira}^{13} .81 .0 \%$ can write and $51.5 \%$ completed secondary education ${ }^{14}$. Almost half of the respondents in our sample is Muslim (48.2\%), 51.1\% is Christian among which $9.3 \%$ are Catholic. ${ }^{15}$ Yoruba is the most prevalent mother tongue $(75.2 \%)$, Igbo is second prevalent with $18.1 \%$ of the respondents.

\subsection{HIV/AIDS knowledge, risk perceptions, and behavior}

Essential to HIV prevention is knowledge on the existence of HIV/AIDS, which we measured by responses to the question: Have you ever heard of HIV/ AIDS?

We measure HIV prevention knowledge, using the answers to the interview question: What can someone do to reduce the risk of contracting HIV? Respondents could give up to four responses. ${ }^{16}$ From these, we constructed a prevention knowledge indicator ranging from 0 to 11 by assigning points for good answers, and subtracting points for giving bad answers. ${ }^{17}$

\footnotetext{
${ }^{10}$ From household members aged 12 years and older blood was collected after informed consent was given (for aged 18 and younger consent needed to be given by one of the parents). 8 drops of blood were collected in a EDTA tube by making a puncture at the finger tip using a sterile lancet. HIV-Status of the respondents was determined using Determine HIV-1/2 rapid test, a standard WHO approved rapid screening test. Respondents were also screened for Malaria, Diabetes Mellitus, and Anemia based on blood tests. Moreover, anthropometric measurements were performed for length, weight, waist-circumference, and blood pressure.

${ }_{11}$ Note that using this definition our household head can be different from the traditional household head.

12 Based on Wilcoxon rank-sum test.

${ }^{13}$ US $\$ 1=60.23$ Naira in PPP (2005). Thus on average they had an annual income of US $\$ 7,745$ expressed in PPP (2005). Using exchange rate during survey period only, thus not corrected for PPP, then annual income is US $\$ 4,057$ $\left(100\right.$ Naira $\approx 0.86964$ US Dollar in July $\left.14^{\text {th }}, 2008\right)$

$1483.7 \%$ completed primary education and $17.2 \%$ completed tertiary education.

15 Only $0.23 \%$ has a traditional religion.

${ }_{16}$ Only $8.1 \%$ was able to mention four prevention methods; $26.6 \%$ was able to mention three methods.

${ }_{17}$ Good answers included, abstaining from sex, using condoms, limiting sex to one partner (2 points). Middle good answers included limit the number of sexual partners, avoiding sex with prostitutes, avoiding having sex with persons having many partners, avoiding sex with homosexuals, avoiding sex with persons who inject drugs intravenously (1
} 
Respondents who never heard of HIV/AIDS were automatically set to 0. Among respondents that ever heard of HIV/AIDS, $83.4 \%$ scored 5 or higher. Three other prevention knowledge measures includes knowledge on each of the famous ABC (Abstain, Be faithful, use Condom). Next to analyzing knowledge on each of the $\mathrm{ABC}$ separately, we constructed a fifth and sixth prevention knowledge indicator showing whether respondents could mention at least one of the $\mathrm{ABC}$ and the full $\mathrm{ABC}$ respectively. Although the majority was able to mention one of the $\mathrm{ABC}$ $(82.2 \%)$, only a small minority was able to mention all three ways to prevent HIV infection $(5.3 \%)$.

Misperceptions on HIV transmission ways may lead to wrong preventive actions. Using a set of three questions, we created a HIV misperception indicator ranging from $0-3$. The indictor includes answers to the following questions: "Can people get HIV/AIDS from mosquito bites?", "Can people get HIV/ AIDS by sharing food with a person who has HIV/ AIDS", and "Is it possible for a healthy looking person to have HIV/AIDS." For each incorrect answer, respondents were penalized by 1 point. For each answer, they did not know 0.5 penalty points were added. Only $2.8 \%$ scored higher than $2,28.0 \%$ scored higher than 1 and $31.8 \%$ scored 0 , i.e. had no misperceptions on the formulated questions.

HIV stigma is considered one of the greatest barriers in preventing further infections. Stigma reduces the provision and demand for the necessary healthcare, increases inconsequent medicine intake, reduces the support for people living with HIV/AIDS (PLWHA), and hinders HIV testing (e.g. Janssens et al. (2009), Mataure (2004), Muyinda et al. (1997), and UNAIDS (2008)). Moreover, stigma reduces safe sexual relations. High stigma levels may discourage raising HIV issues when deciding to have sexual intercourse, reducing condom use among HIV negatives who want to prevent HIV contraction and among HIV positives who want to prohibit HIV transmission. People who feel more confident to raise the issue of condom use during sexual intercourse are indeed more likely to use condoms (Meekers \& Klein 2002). Removing stigma is therefore often seen as an integral component of HIV prevention campaigns (e.g. Reidpath \& Chan (2005)). Our questionnaire includes four stigma related questions focused on fear of casual transmission and refusal of contact with PLWHA. ${ }^{18}$ Based on a similar penalty system used for the misperception indicator, we constructed a stigma indicator ranging from 0 4. Using responses to these four questions, HIV stigma appeared to be highly prevalent among

point). Bad answers included avoid kissing, avoid mosquito bites, seek protection from traditional practitioner, circumcision (-1 point). Zero points were given for avoiding injections or blood transfusion.

${ }^{18}$ Q1: "If you learn that a fresh food vendor is HIV positive, but not sick, would you buy fresh food from him/ her?", Q2: "If a relative of yours became sick with the virus that causes AIDS, would you be willing to care for him/ her in your own households?", Q3: "If a member of your family got infected with HIV, would you want it to remain a secret?", and Q4: "If a teacher is HIV positive but not sick, should she be allowed to continue teaching in school?". 
the market persons; $72.7 \%$ scored 1 or higher, $42.1 \%$ scored 2 or higher, and $11.6 \%$ scored at least 3.

HIV preventive behavior and actual sexual practices, we measured by the following three questions: Q1: "How do you reduce the risk of contracting HIV/AIDS?", Q2: "How many sexual partners did you have during the past 12 months?" and Q3: "Did you use a condom during the last time you've had sex". Based on the responses on the first question, we created an HIV prevention indicator, ranging from $0-12$. We constructed this indicator similarly to the HIV prevention knowledge indicator. Respondents that never heard about HIV/AIDS were again assigned the lowest value, i.e. 0 . Next to this measure, we constructed the $A B C$ prevention indicators described before, but now for actual behavior. In our statistical models, we use the third question last time condom use as dependent variable. Alternatively reported condom use as prevention method could be used, but last time condom use is generally seen as a better proxy for unsafe sexual practices.

Psychometric risk perception scales, we use to measure the perceived risks involved in engaging in unprotected sex, to be able to gain more understanding into why people engage in unprotected sex, while knowing how HIV infection can be prevented. Specifically, as suggested by Blais \& Weber (2006), respondents indicated on a 7-step psychometric scale, how risky they perceive engaging in unprotected sex to be. The involved risk ranged from "Not at all risky" to "Extremely risky". To improve respondents' understanding, the 7-step scale was presented on cards at which respondents had to point at the step most applicable to them (See Appendix A for the distribution of the answer categories and the survey cards with the 7-step Likert-scale). About half of the respondents (49.8\%) indicate unprotected sex as extremely risky, which is only slightly higher among unmarried respondents (50.3\%). Still, $7.5 \%$ of the unmarried indicated engaging in unprotected sex not to be risky at all (versus $15.6 \%$ of the married).

\subsection{HIV knowledge and perception statistics across gender}

Table 2.1 presents an overview of the HIV/AIDS knowledge and perceptions indicators across gender. We present the HIV prevention and HIV prevention knowledge indicators only for those financial decision-makers who reported to have ever heard of HIV/AIDS, indicated in the table by a left indent.

Among the financial decision-makers of the households, $89.5 \%$ reported to have heard of HIV/AIDS before. ${ }^{19}$ This percentage is lower than the country average measured four years preceding our survey (NLSS, 2004), when $92.9 \%$ had ever heard of HIV/AIDS. The (small)

\footnotetext{
$1980.8 \%$ in the full survey sample.
} 
difference is possibly related to the specific characteristics of our group. ${ }^{20}$ There is a clear and significant difference between males and females: $5.5 \%$ of the males never heard of HIV/AIDS, but no less than $15.3 \%$ of the females $(\mathrm{p}<0.001$ on the difference). This difference is also prevalent among the non-main decision-makers of the household, though there it is not significant: $\mathrm{p}=0.117$. Also among respondents who have heard of HIV, males score significantly

${ }^{20}$ Persons operating in the informal sector are more likely to be less educated. Knowledge on HIV is likely to be lower among lower educated (Lagarde et al. 2001). 
Table 2.1 - HIV knowledge \& behavior for household's main financial decision-maker

\begin{tabular}{|c|c|c|c|c|c|}
\hline Variable & Obs. & $\begin{array}{c}\text { Total } \\
\text { sample }\end{array}$ & Male & Female & $\begin{array}{l}\text { p-value } \\
\left(H_{0}: M=F\right)\end{array}$ \\
\hline \multicolumn{6}{|l|}{ Knowledge on the existence of HIV/AIDS } \\
\hline Never heard of HIV/AIDS & 1,929 & $10.5 \%$ & $5.5 \%$ & $15.3 \%$ & 0.0000 \\
\hline \multicolumn{6}{|l|}{ HIV prevention knowledge } \\
\hline \multicolumn{6}{|l|}{$\begin{array}{l}\text { Based on subsample of those who DID hear } \\
\text { from HIV/AIDS: }\end{array}$} \\
\hline $\begin{array}{l}\text { HIV prevention knowledge indicator }(0-11)^{21} \\
\text { average score }\end{array}$ & 1,727 & 6.50 & 6.69 & 6.29 & 0.0000 \\
\hline $\begin{array}{l}(\mathrm{kA}) \text { Mentions abstaining from sex can } \\
\text { prevent HIV contraction }\end{array}$ & 1,726 & $24.3 \%$ & $22.7 \%$ & $26.1 \%$ & 0.1006 \\
\hline $\begin{array}{l}\text { (kB) Mentions being faithful can prevent HIV } \\
\text { contraction }\end{array}$ & 1,726 & $51.7 \%$ & $50.4 \%$ & $53.1 \%$ & 0.2699 \\
\hline $\begin{array}{l}\text { (kC) Mentions condoms can prevent HIV } \\
\text { Infection }\end{array}$ & 1,726 & $43.3 \%$ & $54.3 \%$ & $31.2 \%$ & 0.0000 \\
\hline Mentions one of the $\mathrm{ABC}$ & 1,726 & $82.2 \%$ & $87.1 \%$ & $76.6 \%$ & 0.0000 \\
\hline Mentions ABC & 1,726 & $5.3 \%$ & $5.1 \%$ & $5.6 \%$ & 0.6506 \\
\hline Does not know where to get condom & 1,932 & $19.4 \%$ & $9.4 \%$ & $29.1 \%$ & 0.0000 \\
\hline \multicolumn{6}{|l|}{ HIV related perceptions } \\
\hline Stigma indicator $(0-4)$ & 1,937 & 2.12 & 2.05 & 2.20 & 0.0040 \\
\hline Misperception indicator HIV contraction (0-3) & 1,937 & 0.847 & 0.812 & 0.882 & 0.0118 \\
\hline Perceived lifetime HIV contraction risk (1-4) & $1,766^{22}$ & 1.278 & 1.267 & 1.272 & 0.0619 \\
\hline Risk perception of unprotected sex & 1,914 & 5.459 & 5.52 & 5.403 & 0.2585 \\
\hline \multicolumn{6}{|l|}{$\underline{\text { HIV related behavior }}$} \\
\hline HIV prevention indicator $(0-12)$ & 1,727 & 6.16 & 6.30 & 6.01 & 0.0001 \\
\hline $\begin{array}{l}\text { (A) Mentions to abstain from sex to prevent } \\
\text { HIV contraction }\end{array}$ & 1,726 & $17.1 \%$ & $14.3 \%$ & $20.2 \%$ & 0.0012 \\
\hline $\begin{array}{l}\text { (B) Mentions to be faithful to prevent HIV } \\
\text { contraction }\end{array}$ & 1,726 & $50.8 \%$ & $49.4 \%$ & $52.4 \%$ & 0.2246 \\
\hline (C) Uses condoms to prevent HIV & 1,726 & 37.1 & 47.0 & 26.3 & 0.0000 \\
\hline Used condom last time sex & 1,961 & $18.9 \%$ & $27.8 \%$ & $10.1 \%$ & 0.0000 \\
\hline Had more than one sexual partner in past year & 1,855 & $12.8 \%$ & $23.8 \%$ & $1.9 \%$ & 0.0000 \\
\hline $\begin{array}{l}\text { Married respondents that had more than one } \\
\text { sexual partner in the past year }\end{array}$ & 1,258 & $10.5 \%$ & $19.6 \%$ & $1.9 \%$ & 0.0000 \\
\hline HIV prevalence & 964 & $1.45 \%$ & $0.84 \%$ & $2.06 \%$ & 0.1143 \\
\hline
\end{tabular}

better on the prevention knowledge indicator. Men in particular have better knowledge on condoms: Over $50 \%$ of them mention condoms as a way to prevent HIV infection, whereas only

\footnotetext{
${ }^{21}$ These results are calculated only for those respondents who ever heard of HIV. We also calculated these numbers when including those never heard of HIV, but this does hardly change the results. Difference in abstaining from sex became much less significant $\mathrm{p}=0.78$.

22171 subjects did not respond to this question.
} 
slightly over $30 \%$ of the women mention this as possible prevention measure. Although $85.4 \%$ of our respondents were able to mention at least one of the $\mathrm{ABC}$, only $5.5 \%$ was able to mention all three of them. Males are more able to mention one of the ABC $(87.1 \%(\mathrm{M})$ vs. $76.6 \%(\mathrm{~F})$, $\mathrm{p}<0.0001)$. This result is mostly driven by knowledge of the prevention value of condoms. We do not observe a significant difference in the ability to mention abstaining from sex and being faithful across the sexes. Nevertheless, information on HIV prevention seems to have reached the males better than the females in the studied sample.

Obviously, knowledge on where to get condoms by at least one of the sexual partners is a prerequisite for using condoms. An alarmingly large percentage of females do not know where to get condoms $(29.1 \%(\mathrm{~F})$ vs $9.4 \%(\mathrm{M}))$, in spite of the fact that condoms are widely available in Lagos, and at low cost (Koster, 2003). In 2009, the cheaper brands sold for only 6.67 Naira (about 0.06 US\$) each. ${ }^{23}$ In Lagos, condoms are sometimes given out freely by NGOs working on sexual and reproductive health when conducting outreaches to specific target groups like commercial sex workers, students etc., but Table B.1 in Appendix B shows that condoms are mainly obtained from pharmacies/drugstores and shops (96.8\%). None of the respondents got them in bars or schools and only $2.3 \%$ mentioned getting them in clinics. Females obtained condoms relatively more frequently at clinics $(1.2 \%(\mathrm{M})$ vs. $3.6 \%(\mathrm{~F}))$. There was no significant knowledge difference on where to get condoms between married and unmarried persons for either of the sexes: $\mathrm{p}=0.507$ for both, $\mathrm{p}=0.340$ for Males and $\mathrm{p}=0.789$ for Females.

Although the stigma indicator and misperception indicator do not differ much between males and females, the indicators are significantly lower among males, so males also score better on HIV related perceptions. Remarkably, the risk perception of unprotected sex does not significantly differ across the sexes $(\mathrm{p}=0.259)$.

The knowledge plus for males is also reflected in their sexual behavior: Among those who ever heard of HIV/AIDS, men also more likely use HIV prevention methods. They score better on the general HIV prevention indicator, they are more likely to use condoms to prevent HIV contraction, and more often used condoms the last time they had sexual intercourse $(27.8 \%$ (M) vs. $10.1 \%(\mathrm{~F}), \mathrm{p}<0.001)$. This level is comparable to the $25 \%$ Adih \& Alexander (1999) found among young Ghanaian men. Singles used condoms significantly more than married persons (among males $46.4 \%$ vs. $18.7 \%, \mathrm{p}<0.001$; among females $15.5 \%$ vs. $7.8 \%, \mathrm{p}<0.001$ ). Males on average abstain less from sex as HIV prevention measure (though not significantly so) and report significantly more often to have more sexual partners $(23.8 \%$ (M) vs. $1.9 \%(\mathrm{~F}), \mathrm{p}<0.001)$ compared to females. Blood tests, however, show that HIV prevalence among the females is

\footnotetext{
${ }^{23}$ Using one condom per day would increase per capita overall consumption of non-condom users with $1 \%$.
} 
more than two times higher $(0.8 \%(\mathrm{M})$ vs. $2.1 \%(\mathrm{~F}))$, a disproportionate share often found in the literature (e.g. UNAIDS (2008), Fortson (2008)).

Even given the knowledge gap, the behavioral gap between the sexes is large. De Walque (2007) suggest that this behavioral gap can partly be attributed to an underreporting bias of promiscuous behavior by female, which she supports with prevalence data studied among discordant couples: Between 30-40\% of infected discordant couples appeared to be discordant female. However, the study did not use details on how and when infection took place, e.g during voluntary sex, or during marriage or before. Also in-depth studies show higher promiscuous behavior (including paid sex) among males: in Cotonou, 30\% of males were predicted to have had sex with a female sex worker in 1997 (Lowndes et al. 2008). The higher number of sexual partners could as well explain why males have more knowledge on HIV related issues: Promiscuous behavior demands more knowledge and protection. The next section statistically analyses which knowledge factors could enhance condom use for each of the sexes.

\section{Statistical analysis}

We explain risky sexual behavior by analyzing last time condom use among our sample using a Probit estimation model, in which we correct for potential clustering at the market level. The analysis excludes respondents that are irrelevant for the analysis: First, we exclude those respondents that never had sex $(n=52)$. Second, we exclude respondents who did not have sexual intercourse in the past 12 months $(n=159)$. We thus also exclude those respondents who might have chosen to abstain from sex as a way of preventing HIV contraction: $20.1 \%$ of these indicated to abstain from sex as HIV prevention measure. Among those who did have sexual contacts during the past 12 months, the abstinence percentage was $14.1 \%$. We focus on respondents that did have sexual intercourse during the past 12 months because the explanatory variables cover either current knowledge or behavior over the past 12 months, and current knowledge cannot influence past behavior. Finally, we exclude respondents that indicate to have used condoms to avoid pregnancy $(\mathrm{n}=174)$, as their use is not aimed at avoiding sexually transmitted diseases (STDs). This leaves us with a sample of 1,554 sexually active respondents. ${ }^{24}$

The statistical model controls for age, gender, educational level, and marital status. We classified age in three age groups: young adults $(18-24, \mathrm{n}=55)$, adults $(25-49, \mathrm{n}=1,131)$, and elderly $(50+, n=355)$. We include the following additional control variables: A dummy variable for not knowing where to get a condom $(n=272)$, which can be expected to reduce the likelihood of

${ }^{24}$ Due to missing observations for the included socio-economic explanatory variables, the total number of observations in the statistical models is $6 \%$ lower than in the sample. 
using condoms. We include the dummy variable "Birth control no condom" to analyze whether condom use differs in partners already using a way of birth control different from a condom ( $\mathrm{n}=136)$. Moreover, we include the variable "Wants child, one partner", to control for faithful respondents that indicated the desire of having a child within one year $(n=271)$. Obviously, these respondents cannot fulfill their child wish when using condoms. It does not make sense to classify their unprotected behavior as risky in the same way as for those respondents not having a close-future child wish, or having more sexual partners.

Table 3.1 below shows estimation results for the full sample and for males and females separately. Model 1a shows higher risk perception of engaging in unprotected sex increases the propensity to use condoms. Respondents that perceive engaging in unprotected sex as extremely risky are $34.2 \%$ more likely to have used condoms the last time they had sexual intercourse compared to respondents not viewing any risk at all. Risk perceptions are clearly important in the decision whether to use condoms or not, which is in line with Meekers and Klein (2002).

Table 3.1 - Condom use last time across gender

\begin{tabular}{|c|c|c|c|c|c|c|c|c|c|}
\hline \multirow[t]{2}{*}{ Condom use last time } & \multicolumn{3}{|c|}{$\begin{array}{l}\text { Model 1a } \\
\text { (All) }\end{array}$} & \multicolumn{3}{|c|}{$\begin{array}{l}\text { Model 1b } \\
\text { (Males) }\end{array}$} & \multicolumn{3}{|c|}{$\begin{array}{l}\text { Model 1c } \\
\text { (Females) }\end{array}$} \\
\hline & \multicolumn{2}{|c|}{ Coefficient } & \multirow{2}{*}{$\begin{array}{c}\text { Std. Err. } \\
(0.021)\end{array}$} & \multicolumn{2}{|c|}{ Coefficient } & \multirow{2}{*}{$\begin{array}{c}\text { Std. Err. } \\
(0.023)\end{array}$} & \multicolumn{2}{|c|}{ Coefficient } & \multirow{2}{*}{$\begin{array}{r}\text { Std. Err. } \\
(0.035)\end{array}$} \\
\hline Risk perception $(0-7)$ & 0.057 & *** & & 0.074 & *** & & 0.042 & & \\
\hline $\begin{array}{l}\text { HIV prevention } \\
\text { knowledge indicator }\end{array}$ & 0.023 & & $(0.022)$ & 0.011 & & $(0.033)$ & 0.041 & & $(0.036)$ \\
\hline No. of Sexual partners & 0.026 & & $(0.042)$ & 0.017 & & $(0.043)$ & 0.105 & & $(0.178)$ \\
\hline to get condoms & -1.499 & *** & $(0.395)$ & -25 & & - & -1.190 & *** & $(0.406)$ \\
\hline Married & -0.477 & $* * *$ & $(0.097)$ & -0.609 & $* * *$ & $(0.100)$ & -0.310 & ** & $(0.145)$ \\
\hline $\begin{array}{l}\text { Birth control no } \\
\text { condom }\end{array}$ & -0.094 & & $(0.125)$ & -0.246 & & $(0.490)$ & -0.094 & & $(0.138)$ \\
\hline Want child, one partner & -0.362 & $* * *$ & $(0.112)$ & -0.432 & $* * *$ & $(0.146)$ & -0.267 & ** & $(0.131)$ \\
\hline Male & 0.412 & $* * *$ & $(0.150)$ & & & & & & \\
\hline Age $18-24$ & 0.600 & ** & $(0.280)$ & 0.537 & & $(0.399)$ & 0.726 & *** & $(0.276)$ \\
\hline Age $25-49$ & 0.340 & ** & $(0.137)$ & 0.186 & & $(0.250)$ & 0.559 & $* * *$ & $(0.194)$ \\
\hline Educational level & 0.030 & $* * *$ & $(0.010)$ & 0.029 & $*$ & $(0.015)$ & 0.027 & * & $(0.014)$ \\
\hline Constant & -1.914 & *** & $(0.250)$ & -1.266 & *** & $(0.263)$ & -2.308 & $* * *$ & $(0.350)$ \\
\hline Adj. R-squared & 0.156 & & & 0.081 & & & 0.133 & & \\
\hline Observations & 1461 & & & 608 & & & 788 & & \\
\hline
\end{tabular}

Surprisingly, the HIV knowledge indicator is not significant, although there is substantial variation within the sample (see Table B.2 in Appendix B). Prohaska et al. (1990) show that HIV

\footnotetext{
${ }^{25}$ Note that for males no estimates are provided for the variable "does not know where to get condoms", because this variable predicts non-condom use perfectly. All males (64) not knowing where to get condoms had to necessarily dropped from the analysis.
} 
knowledge has a positive, though insignificant, effect on risk perception, suggesting possible multi-collinearity in our model specification. But the HIV knowledge indicator and the risk perception variable are not highly correlated $(0.13, \mathrm{p}<0.001)$ Although removing the risk perception does improve the significance of this HIV knowledge indicator, it still does not become significant even at the $10 \%$ level. Not surprisingly, not knowing where to get a condom decreases the propensity to use condoms substantially. And $17.6 \%$ of our sample does not know where to get a condom, so the use of condoms can potentially be enhanced by providing this information within this group.

Being married also reduces condom use. While this seems logical, a large share of new infections takes place in married couples (UNAIDS, 2009). Bosu et al. (2009) show that low-risk heterosexual contact accounted for 30\% of new incidence in Ghana. This was not convincingly related to own promiscuous behavior: $43 \%$ of these got infected because the partner had engaged in casual sex. Together with the relatively high tolerance for non-marital partnerships among the married in some African countries (Mngadi et al. 2009), being married will not protect partners sufficiently from getting infected. Faithful respondents that want to have a baby within one year, are also less likely to have used a condom the last time they had sexual intercourse, obviously in line with expectations. Sexually active elderly are less likely to use condoms, and young adults (1824) are almost two times more likely to use condoms than adults (25-49). More highly educated persons are more likely to use condoms than people with less education, as also found by e.g. Pranitha \& Cleland (2005), Koster (2003), but the impact in our sample is relatively small. The propensity to use condoms is much higher for males (the male dummy variable, has a highly significant coefficient of 0.41 ), even though the number of sexual partners is a separate variable; even after controlling for differences in number of sexual partners, males are more likely to use condoms during their last intercourse than females report for their partner during their last intercourse. Males using a condom the last time are more likely to have had more sexual partners (admittedly with weak significance in our sample, $\mathrm{p}=0.089$ ) and are thus potentially more at risk. The regression results show however that a higher number of sexual partners does not lead to more condom use (see Appendix B, Table B.3 for details). To obtain more insight into the reason for higher condom use among males, we analyze last time condom use for both sexes separately (model 1b, 1c).

The propensity to use condoms remains less for both married males and married females than for their unmarried counterparts. The same holds for not knowing where to get condoms. Other predictors are different between the sexes. The risk perception coefficient is higher for males and becomes insignificant for females. Although the prevention knowledge indicator 
remains insignificant for both sexes, it is highly insignificant for males. This suggests that it is not general HIV prevention knowledge that stimulates males' condoms use.

It is remarkable that the risk perception of engaging in unprotected sex is insignificant for females. Contrary to our results, Pranitha \& Cleland (2005), using data on couples from South Africa, find that the perception by wives of their risk of getting HIV from their partner is positively related to condom use. Other social norms or a lack of bargaining power by Lagos females might explain our results. Before drawing any conclusions, however, we first analyze the awkward result that the general HIV knowledge indicator is insignificant for both sexes in more detail by replacing the indicator by six different HIV knowledge indicators in our model.

For each of the knowledge indicators presented in Table 2.1, we re-estimated the regressions of our first model replacing the general HIV knowledge indicator by each of these indicators respectively. Note that we keep the risk perceptions of engaging in unprotected sex in each model as this is a separate type of knowledge and found to be highly significant. Table 3.2 shows that the type of HIV knowledge is important and has different impacts across the sexes.

Table 3.2 - HIV knowledge indicator evaluation

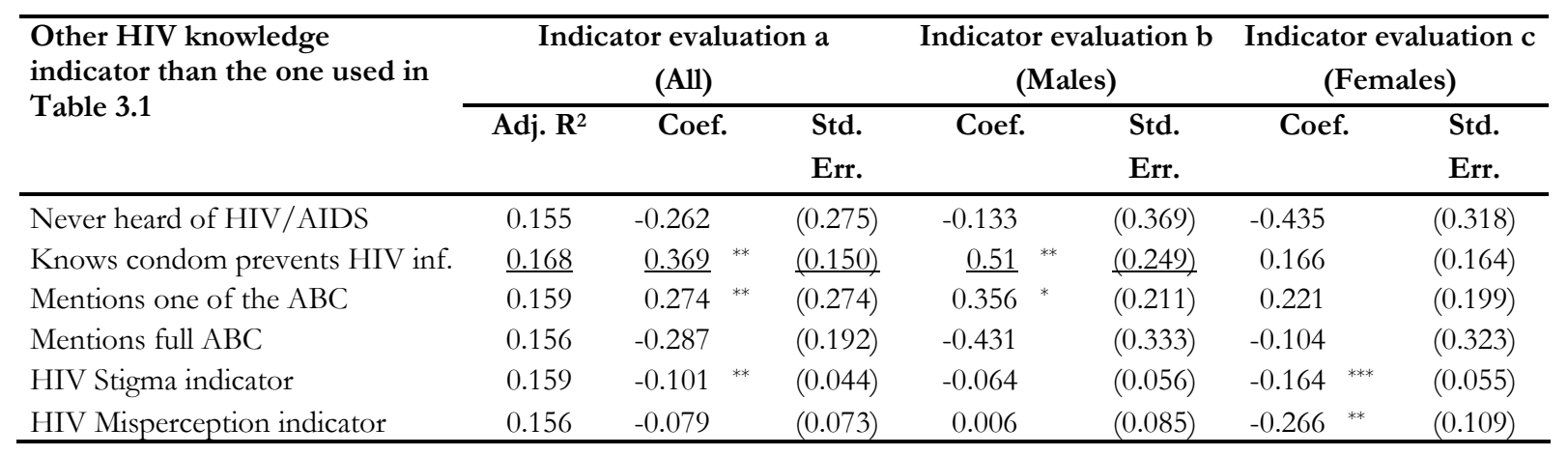

Having only heard of HIV/AIDS does not significantly influence condom use. Although the population share who ever heard of HIV/AIDS may provide an indication of how far information campaigns have reached, it does not seem to tell us anything about the number of potential new infections prevented by this effort, at least it does not seem to lead to more condom use.

In the overall model, knowing that condoms reduce HIV contraction risk does seem to matter: the coefficient is very significant and results in the highest Adjusted $R^{2}(0.168)$. But while it is highly significant for males, it is insignificant for females. Being able to mention one of the $\mathrm{ABC}$ is also significant, but again not for females. The coefficient and the Adjusted $\mathrm{R}^{2}$ are smaller than for the HIV prevention knowledge indicator on condoms only. As expected respondents who scored higher on the stigma indicator, are less likely to use condoms. The propensity to use condoms is also lower among respondents with more misperceptions on HIV contraction ways. 
Both indicators are however not significant for males. These results show that the different components of prevention campaigns, like spreading knowledge about transmission ways and combatting stigma, will all enhance condom use if succesful, but differently across the sexes.

Based on the results of the different HIV knowledge indicators listed in Table 3.2, we formulate a second model including the following HIV knowledge indicators: knowing condoms prevent HIV infection, HIV stigma indicator and the HIV misperception indicator. We do not include the $\mathrm{ABC}$ indicator as its significance was driven by condom knowledge (correlation coeff.: $0.48, \mathrm{p}<0.001) .{ }^{26}$

Model 2b in Table 3.3 shows that male respondents who know that condom use reduces the risk of HIV infection are $51 \%$ more likely to have used a condom the last time they had sexual intercourse. This is thus a high impact factor and relatively easy to influence by means of information campaigns among those who do not yet know this information (characteristics of this group include adults $>24$, married and Muslims).

Table 3.3 - Condom use last time across gender

\begin{tabular}{|c|c|c|c|c|c|c|c|c|c|}
\hline \multirow{3}{*}{$\begin{array}{l}\text { Condom use last time } \\
\text { Risk perception }(0-7)\end{array}$} & \multicolumn{3}{|c|}{$\begin{array}{l}\text { Model 2a } \\
\text { (All) }\end{array}$} & \multicolumn{3}{|c|}{$\begin{array}{l}\text { Model 2b } \\
\text { (Males) }\end{array}$} & \multicolumn{3}{|c|}{$\begin{array}{l}\text { Model 2c } \\
\text { (Female) }\end{array}$} \\
\hline & \multicolumn{2}{|c|}{ Coefficient } & \multirow{2}{*}{$\begin{array}{c}\text { Std. Err. } \\
(0.022)\end{array}$} & \multicolumn{2}{|c|}{ Coefficient } & \multirow{2}{*}{$\begin{array}{c}\text { Std. Err. } \\
(0.021)\end{array}$} & \multicolumn{2}{|c|}{ Coefficient } & \multirow{2}{*}{$\begin{array}{c}\text { Std. Err. } \\
(0.041)\end{array}$} \\
\hline & 0.055 & ** & & 0.071 & *** & & 0.044 & & \\
\hline $\begin{array}{l}\text { Knows condoms prevent HIV } \\
\text { infection }\end{array}$ & 0.357 & ** & $(0.146)$ & 0.508 & ** & $(0.241)$ & 0.131 & & $(0.152)$ \\
\hline HIV stigma indicator & -0.086 & ** & $(0.042)$ & -0.061 & & $(0.053)$ & -0.153 & *** & $(0.058)$ \\
\hline HIV misperception indicator & -0.047 & & $(0.065)$ & 0.045 & & $(0.077)$ & -0.253 & ** & $(0.111)$ \\
\hline No. of Sexual partners ${ }^{27}$ & 0.026 & & $(0.039)$ & 0.017 & & $(0.039)$ & 0.111 & & $(0.181)$ \\
\hline DK where to get condom & -1.397 & $* * *$ & $(0.405)$ & - & & - & -1.062 & ** & $(0.418)$ \\
\hline Married & -0.446 & $* * *$ & $(0.094)$ & -0.579 & $* * *$ & $(0.104)$ & -0.286 & ** & $(0.141)$ \\
\hline Birth control no condom & -0.116 & & $(0.139)$ & -0.425 & & $(0.592)$ & -0.075 & & $(0.146)$ \\
\hline Want child, one partner & -0.392 & $* * *$ & $(0.110)$ & -0.466 & $* * *$ & $(0.152)$ & -0.303 & ** & $(0.139)$ \\
\hline Male & 0.330 & ** & $(0.142)$ & & & & & & \\
\hline Age 18-24 & 0.544 & $*$ & $(0.297)$ & 0.492 & & $(0.420)$ & 0.753 & $* * *$ & $(0.269)$ \\
\hline Age 25-49 & 0.333 & *** & $(0.130)$ & 0.201 & & $(0.244)$ & 0.588 & *** & (0.191) \\
\hline Educational level & 0.025 & ** & $(0.010)$ & 0.024 & * & $(0.013)$ & 0.021 & & $(0.016)$ \\
\hline Constant & -1.628 & *** & $(0.272)$ & -1.369 & $* * *$ & $(0.264)$ & -1.611 & *** & $(0.423)$ \\
\hline Adj. R-squared & 0.172 & & & 0.110 & & & 0.156 & & \\
\hline Observations & 1459 & & & 608 & & & 787 & & \\
\hline
\end{tabular}

Also, males that perceive the risk of engaging in unprotected sex as extremely risky are also $50 \%$

\footnotetext{
${ }^{26}$ Its significance disappears when including the condom knowledge indicator.

${ }^{27}$ Including a dummy variable for having more than one sex partner in the past 12 months, does not improve the model.
} 
more likely to have used a condom compared to those who perceive engaging in unprotected sex as not risky at all. ${ }^{28}$ The data thus show that both HIV prevention knowledge and risk perception are important factors in the propensity to use condoms among males. Note furthermore, that married males and faithful males who would like to have a child within one year, used condoms significantly less often.

Model 2c shows that knowledge on the preventive characteristic of condoms does not improve the propensity to use condoms by women; neither does the risk perception of engaging in unprotected sex. This is a very remarkable result as it suggests that providing direct information on how to prevent HIV infection to females, as currently done in information campaigns, has little effect. Information on where to get condoms is an exception to this. Females that do not know where to get a condom are 100\% more likely to not have used a condom the last time they had sexual intercourse. This group is characterized by adults $24>$, the less educated, and the married. Since one third of the female respondents do not know where to get a condom, (free) distributions of condoms in public places, like condoms automats in clinics, bars or nightclubs, could enhance condom use by these females. Another way to stimulate condom use by females is combating HIV stigma and misperceptions on transmission ways of the virus. Of these two knowledge gaps, misperceptions has the largest negative effect on last time condom use by females.

It is highly remarkable that knowing that condoms can prevent HIV transmission does not influence condom use among females. One explanation for this result could be that females lack bargaining power. Orubuloye et al. (1997) indicate that in Nigeria the culture of male dominance leads to women seldom taking decisions even if it directly affects them. Reduced power makes women less able to negotiate safe sex or to seek proper related healthcare. This male dominance in sexual relations is supported by studies conducted by Andersson et al. (2007) in several other African countries showing that having multiple partners is strongly correlated with physical violence. Moreover, 47\% of men and 40\% of women in Lesotho thought that women have no right to refuse sex with their husbands or boyfriends. Against that, Orubuloye et al. (1997), in their exploratory study conducted in Ekiti state, Nigeria, showed an increasing female decision-making in reproductive health: Among the surveyed group, the majority of the women took the decisions on method and timing of family planning. Koster (2003) provides another anthropological explanation based on a study among Yorubans in Nigeria: "Marriages are contracted in order to produce children, childless marriages are useless.... according to traditional Yoruba custom, women should start bearing children as soon as possible after marriage...Child bearing should not be stopped

28 The correlation between risk perception and knowing that condoms prevent HIV infection is low: 0.0695 $\mathrm{p}=0.0031$ (Both); 0.0702, $\mathrm{p}=0.0380(\mathrm{M})$; and $0.0591, \mathrm{p}=0.0710(\mathrm{~F})$. 
intentionally, but should only end when a woman approaches menopause". In her study, she did not find that male influence played a major role in preventing women from using effective modern contraceptives; however, males did indicate that they were against contraceptives use by married females, as they would make it easier to have secret extramarital affairs.

So the evidence is mixed. To empirically investigate this issue, we analyze the knowledge effect for single and married females separately. To be specific, we include a cross-term for singles who know that condoms prevent HIV infection. In the overall model (model 3a, see Table 3.4), singles who know that condoms can prevent HIV transmission, significantly more often used a condom the last time they had sexual intercourse. Contrary to the insignificance of this knowledge component for females in general, this component is highly significant for unmarried females. The predictive power is relatively large, i.e. +1.239 . Apparently, HIV condom knowledge does enhance condom use among females, but only among singles.

Table 3.4 - Condom use last time across gender with cross term singles

\begin{tabular}{|c|c|c|c|c|c|c|c|c|c|c|c|c|}
\hline \multirow[t]{2}{*}{ Condom use last time } & \multicolumn{3}{|c|}{$\begin{array}{l}\text { Model 3a } \\
\text { (All) }\end{array}$} & \multicolumn{3}{|c|}{$\begin{array}{l}\text { Model 3b } \\
\text { (Males) }\end{array}$} & \multicolumn{3}{|c|}{$\begin{array}{l}\text { Model 3c } \\
\text { (Female) }\end{array}$} & \multicolumn{3}{|c|}{$\begin{array}{c}\text { Model 3d } \\
\text { (Female, IV) }\end{array}$} \\
\hline & \multicolumn{2}{|c|}{ Coefficient } & \multirow{2}{*}{$\begin{array}{l}\text { Std. } \\
\text { Err. } \\
(0.023)\end{array}$} & \multicolumn{2}{|c|}{ Coefficient } & \multirow{2}{*}{$\begin{array}{l}\text { Std. } \\
\text { Err. } \\
(0.022)\end{array}$} & \multicolumn{2}{|c|}{ Coefficient } & \multirow{2}{*}{$\begin{array}{c}\text { Std. } \\
\text { Err. } \\
(0.043)\end{array}$} & \multicolumn{2}{|c|}{ Coefficient } & \multirow{2}{*}{$\begin{array}{c}\text { Std. } \\
\text { Err. } \\
(0.032)\end{array}$} \\
\hline Risk perception $(0-7)$ & 0.053 & ** & & 0.072 & $* * *$ & & 0.032 & & & 0.011 & & \\
\hline $\begin{array}{l}\text { Knows condoms prevent } \\
\text { HIV infection }\end{array}$ & 0.202 & & $(0.161)$ & 0.379 & & $(0.250)$ & -0.088 & & $(0.178)$ & -0.858 & & $(0.140)$ \\
\hline $\begin{array}{l}\text { C Single }+ \text { knows } \\
\text { condoms prevent } \mathrm{HIV} \\
\text { infection }\end{array}$ & 0.826 & *** & $(0.153)$ & 0.605 & *** & $(0.180)$ & 1.239 & $* * *$ & $(0.315)$ & 0.898 & ** & $(0.377)$ \\
\hline HIV stigma indicator & -0.083 & ** & $(0.042)$ & -0.051 & & $(0.051)$ & -0.165 & $* * *$ & $(0.063)$ & -0.858 & $* * *$ & $(0.182)$ \\
\hline $\begin{array}{l}\text { HIV misperception } \\
\text { indicator }\end{array}$ & -0.033 & & $(0.066)$ & 0.062 & & $(0.076)$ & -0.264 & ** & $(0.113)$ & -0.092 & & $(0.117)$ \\
\hline No. of Sexual partners & 0.020 & & $(0.040)$ & 0.014 & & $(0.038)$ & 0.057 & & $(0.188)$ & 0.080 & & $(0.167)$ \\
\hline $\begin{array}{l}\text { Does not Know where to } \\
\text { get condom }\end{array}$ & -1.411 & *** & $(0.411)$ & & & & -1.048 & ** & $(0.412)$ & -0.752 & ** & $(0.350)$ \\
\hline Married & -0.193 & ** & $(0.086)$ & -0.344 & *** & $(0.115)$ & -0.049 & & $(0.125)$ & 0.109 & & $(0.150)$ \\
\hline Birth control no condom & -0.085 & & $(0.134)$ & -0.321 & & $(0.565)$ & -0.035 & & $(0.151)$ & -0.048 & & $(0.161)$ \\
\hline Want child, one partner & -0.353 & *** & $(0.113)$ & -0.433 & *** & $(0.151)$ & -0.279 & * & $(0.147)$ & -0.258 & $*$ & $(0.156)$ \\
\hline Male & 0.306 & ** & $(0.141)$ & & & & & & & & & \\
\hline Age 18-24 & 0.288 & & $(0.307)$ & 0.261 & & $(0.404)$ & 0.496 & & $(0.336)$ & 0.268 & & $(0.338)$ \\
\hline Age 25-49 & 0.258 & ** & $(0.127)$ & 0.148 & & $(0.233)$ & 0.518 & *** & $(0.174)$ & 0.325 & * & $(0.228)$ \\
\hline Educational level & 0.027 & ** & $(0.011)$ & 0.027 & ** & $(0.013)$ & 0.022 & & $(0.017)$ & -0.003 & & $(0.017)$ \\
\hline Constant & -1.756 & *** & $(0.294)$ & -1.549 & $* * *$ & $(0.270)$ & -1.596 & $* * *$ & $(0.398)$ & 0.659 & & $(1.171)$ \\
\hline Adj. R-squared & 0.189 & & & 0.120 & & & 0.190 & & & 192 & Wa & chi \\
\hline Observations & 1459 & & & 608 & & & 787 & & & 775 & & \\
\hline
\end{tabular}

One interpretation is that power relations, and in particular female dependence, become stronger when married. But also one or both of the partners could find condom use not 
acceptable within marriage. This is supported by several studies across the African continent. Orubuloye et al. (1997) for example shows that $25 \%$ of urban females in their surveyed Nigerian group reported to find it unacceptable for females to ask for a condom when having an infected partner; while 30\% was undecided on this. Using semi-structured interviews Chimbiri (2007) shows that condoms are seen an intruder in the domestic space in Malawi which hampers bringing up the topic among married couples.

Married females trusting their partners to not engage in risky sexual behavior could also explain our results, so we analyzed the number of sexual partners among the sexes. In general, females reported less sexual partners compared to males $(p<0.0001)$. Single males are twelve times more likely to have had more than one sexual partner in the past year than single females. This is only little lower amongst married respondents, where males are ten times more likely to have had more than one sexual partner in the past year. It seems more than likely that females are aware of the promiscuous behavior of men. In that context the fact that single females demand condom use significantly more often than their married counterparts points at weak bargaining power of women within marital relations.

Another explanation for the significance of condom knowledge by singles female is given by Koster (2003): Social rules do not accept contraceptive use by single women, because premarital intercourse is culturally not permitted. Even clinics are hesitant to help single women in birth control for this reason. Out of necessity, she argues, single women buy contraceptives from chemists or other suppliers for which no consultation is required. These have a limited range of birth control methods but include condoms, which could partly explain higher condom use among single females.

Note, however, that the impact of knowing that condoms can prevent HIV transmission is highly significant for both single and married males. The significance of the cross-term for males shows that this knowledge is more important when being single. This suggests that such knowledge is also more important when men have sex with a casual partner than when they have sex with their wife. This is supported by the fact that, while $14.3 \%$ of the married men indicated they used a condom last time, only $6.3 \%$ of the married females did so. Males thus seem to have different sexual behavior with their spouse than with a casual partner. We could test this interpretation if we would have had information on with whom respondents had sexual intercourse the last time. Unfortunately, we do not have this information.

A final econometric issue is related to the tendency by women to underreport promiscuous behavior due to societal pressures (De Walque (2007)). Nnko et al. (2004) also find that females underreport non-marital partnerships. There is a reasonable suspicion that if 
extramarital affairs and condom use are positively correlated, and extramarital affairs are underreported, that condom use may be underreported as well. Since we analyze female's condom use separately from males', female underreporting would not affect all our results. It would have been helpful to study condom use among those who already reported extramarital sex, on the assumption that those who already report extramarital sex are less likely to underreport condom use, however, our sample size becomes too small for meaningful econometric results if we restrict the sample to women reporting extramarital affairs. ${ }^{29}$

Underreporting of condom use among females causes a bias in the dependent variable. Econometrically this only causes a problem if the bias is correlated with one of the explanatory variables. The most likely candidate for correlation with the bias is our HIV stigma indicator because fear of stigma is most likely one of the drivers of underreporting. Therefore, we employ an IV estimation with having been tested for HIV and ethnicity as instruments (see Model 3d). The results do not change drastically: the difference between the impact of knowledge about the preventive value of condom use remains highly significant for single women but insignificant for married women. The coefficient for de HIV stigma indicator remains highly significant and becomes substantially larger. Thus (fear of) stigma seems to be an important driver of unsafe sex practices, particularly among married women. The indicator for HIV misperception becomes insignificant but remains negative in sign. Although the pattern emerging from the IV estimates is not drastically different from the OLS estimates, a formal test actually indicates the necessity to use IV methods. The relevant Wu-Hausman test rejects consistency of the OLS estimates. This suggests that there is indeed a potential underreporting bias found among females, and that this bias is correlated with some of the RHS variables, but correcting for it through the use of Instrumental Variables leaves our results largely unaffected (Table 3.4, model 3d).

\section{Conclusions}

Analyzing why people fail to take adequate measures to protect themselves against HIV/AIDS infection is of key importance for the drive to reduce new infections. This paper focuses on how different types of HIV knowledge, including risk perceptions of engaging in unprotected sex, influence condom use across the sexes. We distinguish between the sexes because of often documented lower reported knowledge and lower condom use among females.

We use data from a household survey conducted in 2008 among market persons in

\footnotetext{
29 The exercise however does show some interesting relations: $100 \%$ of those females not knowing where to obtain a condom, those not knowing that condoms prevent HIV transmission, or those scoring higher than 1 on the HIV stigma indicator failed to use a condom at last intercourse. Moreover, $93 \%$ of females having more than two sexual partners did not use a condom at last intercourse.
} 
Nigeria's financial capital Lagos, and show that for males risk perceptions are as important as knowledge on how to prevent HIV infection. Men who perceive the risk of engaging in unprotected sex as extremely high are $22 \%$ more likely to have used a condom the last time of intercourse compared to men who perceive the risk as moderate, and over $50 \%$ more likely compared to those who perceive no risk at all in engaging in unprotected sex.

But we show a large knowledge gap between males and females on HIV related topics, with strong implications for the design of HIV prevention campaigns. Males not only score significantly better on almost all HIV knowledge indicators, they also have less misperceptions on HIV related issues and moreover stigmatize HIV positive individuals less than females do. Overall, information on HIV prevention in Lagos seems to have reached the males better than the females in our sample. These result confirm the findings by Lowndes et al. (2008) who show that comprehensive HIV knowledge is substantially lower among women than among men in most West African countries. Despite this knowledge advantage, men are much more likely to have multiple sexual partners $(23.8 \%$ vs. $1.9 \%)$, which may partially explain why males are $31 \%$ more likely to have used a condom at last sexual intercourse. This latter result is consistent with previous findings reported in the literature that consistently describe more condom use among males (e.g. Biraro et al, 2009, Chimbiri, 2007, Hartung et al. 2002). This paper showed what knowledge types triggers condom use for both sexes.

The HIV knowledge gap between males and females would seem to suggest that HIV prevention campaigns should focus on improving knowledge among women. However, our results show that that may not be enough. Condom use analysis across the sexes shows that neither knowing that a condom protects against HIV nor risk perceptions of engaging in unprotected sex significantly increases the propensity to use condoms among women. This in sharp contrast to males, where HIV knowledge and risk perception do lead to prevention actions. The analysis suggests that asymmetries in bargaining power within marriage are an important factor behind this somewhat disturbing result: among single females, knowledge about the preventive value of condom use and awareness of the risks of unprotected sex does translate into more condom use. Therefore, policies aimed only at reducing unprotected sex are likely to be more efficient when targeted on males and unmarried females.

Preventive behavior across all females could be enhanced by reducing HIV stigma, since this factor reduced condom use among females strongly in our sample. Moreover, knowledge on where to get condoms should be improved. An alarming 30\% of the females did not know where to get a condom and this lack of knowledge had a significantly negative impact on their condom use. Making condoms more available to females by distributing them for example at 
schools/clinics, bars and nightclubs is an option worth considering.

Among our male respondents, condom use can be enhanced by increasing HIV knowledge on the ABC. Though informing them on the $\mathbf{C}$, that condoms are a good method to prevent HIV infection would be the most efficient of the three. In addition, for men also more information should be provided on where they can buy condoms, since still almost $10 \%$ did not know where condoms can be bought despite the wide availability in Lagos. Tellingly, among these males nobody used a condom the last time they had sexual intercourse. Next to knowledge of reducing HIV infection risk by using condoms, the perception of the risk of engaging in unprotected sex among males appears to be very important in the decision of whether to use a condom or not. Influencing this risk perception in HIV prevention programs is underexplored, developing effective methods to increase this risk perceptions seems important.

\section{References}

Adih, W.K. \& Alexander S.C. (1999) "Determinants of condom use to prevent HIV infection among youth in Ghana", Journal of Adolescent Health, Volume 24(1), p. 63-72.

Ahmed, S.; Lutaloa, T.; Wawerb, M.; Serwaddac, D.; Sewankambo, N. K.; Nalugodaa, F.; Makumbia, F.; Wabwire-Mangenc, F.; Kiwanukaa, N.; Kigozia, G.; Kiddugavua, M \& Gray, R. (2001). "HIV incidence and sexually transmitted disease prevalence associated with condom use: a population study in Rakai, Uganda", AIDS, Vol. 15, (16), p. 2171 2179.

AIID-CPCD: Lammers, J.; Lange, J.; Van Spijk, J.; Van der Gaag, J.; de Wit, F; Rooijakkers, J.; Velenyi, E. \& Van der Vlught, G. (2009a). "Impact Evaluation of HIF-supported Health Insurance projects in Nigeria: Preliminary results from the baseline survey in Lagos" AIID-CPCD.

AIID-CPCD, (2009b). "Report on the Republic of Namibia Okambilimbili Survey 2008", Amsterdam

Andersson, N.; Ho-Foster, A.; Mitchell, S.; Scheepers, E. \& Goldstein, S. (2007) "Risk factors for domestic physical violence: national cross-sectional household surveys in eight southern African countries," BMC Women's Health, DOI: 10.1186/1472-6874-7-11.

Biraro, S, L A Shafer, I Kleinschmidt, B Wolff, A Karabalinde, A Nalwoga, J Musinguzi, W Kirungi, A Opio, J Whitworth \& Grosskurth, H. (2009). "Is sexual risk taking behaviour changing in rural south-west Uganda? Behaviour trends in a rural population cohort 1993_2006”, Sexually Transmitted Infections 85: i3-i11.

Blais, A. \& Weber, E. U. (2006) "A Domain-Specific Risk-Taking (DOSPERT) scale for adult populations", Judgment and Decision Making, Vol. 1(1), p. 33-47.

Bosu W.K. et al. (2009). Modes of HIV transmission in West Africa: analysis of the distribution of new HIV infections in Ghana and recommendations for prevention.

Chimbiri, A.M. (2007). "The condom is an 'intruder' in marriage: evidence from rural Malawi”, Social Science \& Medicine, Vol. 64, p. 1102-1115.

Dunkle, K. L.; Jewkes, R. K.; Brown, H. C.; Gray, G. E.; McIntryre, J. A. \& Harlow, S. D. (2004), "Gender-based violence, relationship power, and risk of HIV infection in women attending antenatal clinics in South Africa", The Lancet, Vol. 363, p. 1415-1421.

Fortson J. (2008). "The Gradient in Sub-Saharan Africa: Socioeconomic Status and HIV/AIDS", Demography, Vol. 45(2), p. 303-322. 
Hartung, T.K., J. Nash, N. Ngubane and Fredlund, V.G. (2002). "AIDS awareness ans sexuall behavior in a high HIV prevalence area in rural northern Kwazulu-Natal, South Africa", International Journal of STD \& AIDS, Vol. 13, p. 829-832.

Koster, W. (2003). "Secret strategies: woman and abortion in Yoruba society, Nigeria", Health culture and society, Studies in medical anthropology and sociology, Aksant, ISBN 905260-103-8.

Lagarde, E.; Auvert, B.; Chege, J.; Sukwa, T.; Glynn, J. R.; Weiss, H. A.; Akam, E.; Laourou, M.; Caraël, M. \& Buvé, A. (2001). "Condom use and its association with HIV/sexually transmitted diseases in four urban communities of sub-Saharan Africa", the Study Group on the Heterogeneity of HIV Epidemics in African Cities, AIDS, Vol. 15 Suppl. 4 p. S71S78, August.

Lagarde, E.; Caraël, M.; Glynn, J. R.; Kanhonou L.; Abega SC.; Kahindo M.; Musonda R.; Auvert, B. \& Buvé, A. (2001). "Educational level is associated with condom use within nonspousal partnerships in four cities of sub-Saharan Africa", AIDS, Vol. 15, p. 1399-1408.

Lowndes, C.M., Alarly, M.; Belleau, M.; Bosu, W.K.; Kintin, D.F.; Nnorom, J.A.; Seck, K.; Victor-Ahuchogu, J. \& Wilson, D. (2008). Western Africa HIV/AIDS epidemiology and response synthesis: Characterization of the HIV epidemic and response in West Africa: implications for prevention. Washington, DC, World Bank.

Macintyre, K.; Brown, L. \& Sosler, S. (2001). "It's not what you know, but who you knew: examining the relationship between behavior change and AIDS mortality in Africa", AIDS Education Preview, Vol. 13(2), p. 160-174.

Magnani, R.J.; Karim, A.M.; Weiss, M.S.; Bond K.C, Lemba, M. \& Morgan, G.T. (2002). "Reproductive health risk and protective factors among youth in Lusaka, Zambia", Journal of Adolescent Health, Vol. 30(1), p.76-86.

Meekers, D. \& Klein, M. (2002). "Determinants of condom use among young people in urban Cameroon", Studies in Family Planning, Vol. 33(4), p.335-346.

Muyinda, H.; Seeley, J.; Pickering, H. \& Barton, T. (1997). "Social aspects of AIDS-related stigma in rural Uganda", Health and Place, Vol. 3(3), p. 143-147.

Nnko, S.; Boerma, J.T.; Urassa, M.; Mwaluko, G. \& Zaba, B. (2004). "Secretive females or swaggering males?: An assessment of the quality of sexual partnership reporting in rural Tanzania”, Social Science \& Medicine, Vol. 59(2), p. 299-310.

Opio, A.; Mishra, V.;Hong, R.; Musinguzi, J., Kirungi, W.; Cross, A.; Mermin, J.; Bunnell, R. (2008). "Trends in HIV-related behaviors and knowledge in Uganda, 1989-2005: evidence of a shift toward more risk-taking behaviors." Journal of Acquired Immune Deficiency Syndromes, Vol. 49, p. 320-326.

Orubuloye, I.O.; Oguntimehina, F. \& Sadiq, T. (1997). "Women's role in reproductive health decision making and vulnerability to STD and HIV/AIDS in Ekiti, Nigeria", Health Transition Review, Supplement to Vol. 7, p. 329-336.

Pinkerton S.D. \& Abramson P.R. (1997). "Effectiveness of condoms in preventing HIV transmission", Social Science \& Medicine, Vol. 44, p. 1303-1312.

Pranitha, M. \& Cleland, J., (2005). "Risk Perception and Conddom Use among Married or Cohabiting Couples in KwaZulu-Natal, South Africa", International Family Planning Perspectives, Vol. 31(1), p. 24-29.

Prata, N.; Morris, L.; Mazive. E.; Vahidnia, F.; Stehr, M. (2006). "Relationship Between HIV Risk Perception And Condom Use: Evidence from a Population-Based Survey in Mozambique", International Family Planning Perspectives, Vol. 32(4), p. 192-200.

Prohaska, T.R.; Albrecht, G.; Levy, J.A. ; Sugrue, N. ; Kim, J.H. (1990), "Determinants of selfperceived risk for AIDS", Journal of Health and Social Behavior, 1990, Vol. 31(4), p. 384-394.

Reidpath, D.D. \& Chan, K.Y. (2005). "A method for the quantitative analysis of the layering of HIV-related stigma", AIDS Care, May 2005, Vol. 17(4), p. 425-432.

Royce, R.A., Sena A., \& Cates W. Cohen M.S. (1997) "Sexual Transmission of HIV/AIDS." The 
New England Journal of Medicine, Vol. 336(15)

Sahlu, T., Kassa, E., Agonafer, T., Tsegaye, A., Rinke de Wit, T., Gebremariam, H., Doorly, R., Spijkerman, I., Yeneneh, H., Coutinho, R. \& Fontanet, A. (1999). "Sexual behaviours, perception of risk of HIV infection, and factors associated with attending HIV post-test counseling in Ethiopia", AIDS, Vol. 13(10), p. 1263-1272.

Seeley, J. A.; Malamba, S. S.; Nunn, A. J.; Mulder, D. W.; Kengeya-Kayondo, J. F.; Barton, T. G. (1994). "Socioeconomic Status, Gender, and Risk of HIV-1 Infection in a Rural Community in South West Uganda", Medical Anthropology Quarterly, New Series, Vol. $8(1)$, p. $78-89$.

De Walque, D. (2007). "Sero-discordant Couples in Five African Countries: Implications for Prevention Strategies," Population and development Review, Vol. 33(3), p. 501-523.

De Walque, D. (2009). "Comparing Condom Use with Different Types of Partners: Evidence from National HIV Surveys in Africa," Policy Research Working Paper 5130, The World Bank Development Research Group, November 2009.

Williams, B.G; Taljaard, D.; Campbell, C.M.; Gouws, E.; Ndhlovu, L.; van Dam, J.; Caraël, M.; Auvert, B. (2003). "Changing patterns of knowledge, reported behaviour and sexually transmitted infections in a South African gold mining community," AIDS: Vol. 17(14), p. 2099-2107.

Weller, S.C. \& Davis-Beaty, K. (2002), "Condom effectiveness in reducing heterosexual HIV transmission." Cochrane Database of Systematic Reviews, Issue 1. Art. No.: CD003255. DOI: 10.1002/14651858.CD003255.

UNAIDS (2005). Intensifying HIV prevention: A UNIADS policy position paper. Geneva. ISBN 929 1734373.

UNAIDS (2008), Report on the global AIDS epidemic, Geneva. ISBN 9789291737116.

UNAIDS-WHO (2009). AIDS epidemic update, November 2009, Geneva. ISBN 9789291738328.

\section{Appendix A: Survey card with psychometric scales and responses}

Q: "How risky do you perceive engaging in unprotected sex?"

\begin{tabular}{|llllllllll|}
\hline & $\begin{array}{c}\text { Not at all } \\
\text { Risky }\end{array}$ & $\begin{array}{c}\text { Slightly } \\
\text { Risky }\end{array}$ & $\begin{array}{c}\text { Somewhat } \\
\text { Risky }\end{array}$ & $\begin{array}{c}\text { Moderately } \\
\text { Risky }\end{array}$ & Risky & Very Risky Extremely \\
Risky
\end{tabular}

Figure A.1: Risk card 


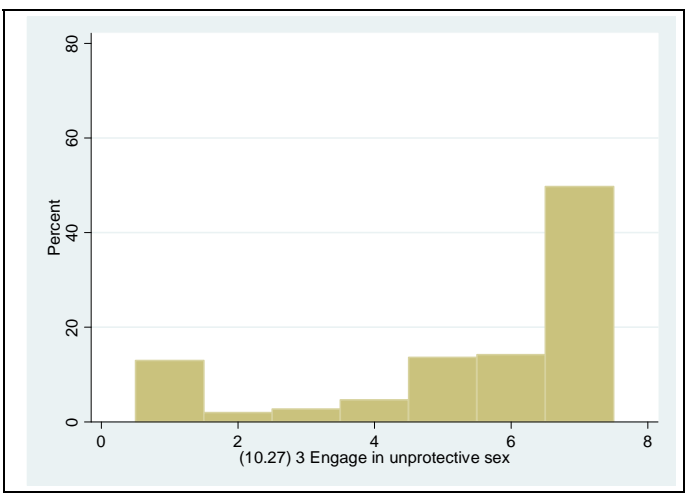

Figure A.2: Distribution of Risk perception answers

\section{Appendix B: Tables}

Table B.1 - Obtaining condoms

\begin{tabular}{lcccc}
\hline & $\mathbf{N}$ & All & Males & Females \\
\hline Shops & 254 & $16.3 \%$ & $12.4 \%$ & $21.2 \%$ \\
Pharmacy/drugstore & 1,253 & $80.5 \%$ & $85.3 \%$ & $74.6 \%$ \\
Clinics & 35 & $2.25 \%$ & $1.16 \%$ & $3.62 \%$ \\
Workplace & 3 & $0.19 \%$ & $0.35 \%$ & $0.00 \%$ \\
Bar/School & 0 & $0.00 \%$ & $0.00 \%$ & $0.00 \%$ \\
Other & 12 & $0.77 \%$ & $0.81 \%$ & $0.58 \%$ \\
\hline Total & $\mathbf{1 , 5 5 7}$ & $\mathbf{1 0 0} \%$ & $\mathbf{1 0 0} \%$ & $\mathbf{1 0 0} \%$ \\
\hline Don't know & 375 & $19.4 \%$ & $9.4 \%$ & $29.1 \%$ \\
\hline
\end{tabular}

Table B.2 - HIV prevention knowledge indicator

\begin{tabular}{cccc}
\hline Indicator & Freq. & All & Cum $\%$. \\
\hline $\mathbf{0}^{* *}$ & 200 & $11.7 \%$ & 11.7 \\
$\mathbf{3}$ & 70 & $4.1 \%$ & 15.8 \\
$\mathbf{4}$ & 167 & $9.8 \%$ & 25.6 \\
$\mathbf{5}$ & 43 & $2.5 \%$ & 28.2 \\
$\mathbf{6}$ & 636 & $37.3 \%$ & 65.5 \\
$\mathbf{7}$ & 91 & $5.3 \%$ & 70.8 \\
$\mathbf{8}$ & 342 & $20.1 \%$ & 90.9 \\
$\mathbf{9}$ & 72 & $4.2 \%$ & 95.1 \\
$\mathbf{1 0}$ & 79 & $4.6 \%$ & 99.7 \\
$\mathbf{1 1}$ & 5 & $0.3 \%$ & 100.0 \\
\hline Total & 1,705 & $100 \%$ & \\
\hline
\end{tabular}

₹ Using sample regression Model 1

${ }^{* *}$ ) Note that 191 out of these 200 individuals never heard of HIV/AIDS. 
Table B.3 - Preventive behavior and number of partners*

\begin{tabular}{lcccccc}
\hline & \multicolumn{2}{c}{ All } & \multicolumn{2}{c}{ Males } & \multicolumn{2}{c}{ Females } \\
\cline { 2 - 7 } & $\begin{array}{c}\text { mean } \\
\text { \# partners }\end{array}$ & Std Err & $\begin{array}{c}\text { mean } \\
\text { \# partners }\end{array}$ & Std Err & $\begin{array}{c}\text { mean } \\
\text { \# partners }\end{array}$ & Std Err \\
\hline No condom last time & 1.19 & 0.81 & 1.39 & 1.16 & 1.02 & 0.20 \\
Condom last time & 1.42 & 1.54 & 1.58 & 1.83 & 1.06 & 0.40 \\
p-value & 0.0001 & & 0.089 & & 0.471 & \\
\hline
\end{tabular}

) Using sample regression Model 1 